\title{
Production of Single-walled \\ Cysts of Schizopyrenus russelli by Sonication and their Behaviour Towards Excystment-inducing and Excystment-blocking Agents
}

\author{
By A. K. RASTOGI, P. SAGAR And S. C. AGARWALA \\ Central Drug Research Institute, Lucknow, India \\ (Accepted for publication 21 November 1969) \\ SUMMARY
}

Ultrasonic treatment of double-walled cysts of Schizopyrenus russelli led to the removal of the outer wall. These single-walled cysts excysted readily in aqueous extract of Escherichia coli, as did normal double-walled cysts. There was a marked delay in the excystment of single-walled cysts obtained by ultrasonic treatment of the normal cysts treated with $p$-chloromercuric benzoate $(p-\mathrm{CMB})$ or emetine, similar to that obtained with normal cysts. The action of $p$-CMB was annulled by reduced glutathione. These findings suggest that the sites of action of excystment-inducing and excystmentblocking agents are on or inside the inner cyst wall and that these agents are able to permeate the outer cyst wall.

\section{INTRODUCTION}

Earlier work has shown that aqueous extracts of either Aerobacter species or Escherichia coli, or certain amino acids, are able to cause excystment of double-walled cysts of the amoeba Schizopyrenus russelli Singh (Singh, Mathew \& Anand, 1958). Emetine inhibited the induction of excystment by these agents (Imam, Dutta \& Agarwala, 1968) and $p$-chloromercuric benzoate ( $p$-CMB) delayed the emergence of trophozoites from the cysts (Rastogi, Sagar \& Agarwala, 1969). This action of $p$-CMB was annulled by reduced glutathione. The present paper deals with the production of single-walled cysts of $S$. russelli by ultrasonic treatment and their behaviour towards excystment-inducing and excystment-blocking agents.

\section{METHODS}

Schizopyrenus russelli was grown in monobacterial culture with Escherichia coli. Viable sterile cysts, free from bacteria, were obtained by the method reported earlier (Rastogi et al. $\mathrm{I} 969$ ). A suspension of $\mathrm{IO} \times \mathrm{IO}^{6} \mathrm{cysts} / \mathrm{ml}$. was made and stored in a refrigerator. Ultrasonic treatment was done for periods up to Io min. in $8 \mathrm{ml}$. lots of cyst suspension in distilled water containing $2 \times 10^{7}$ cysts in a $50 \mathrm{ml}$. beaker, chilled in crushed ice, by using a Mullard ultrasonic generator fitted with $20 \mathrm{kc}$. transducer (output current I 5 amperes). The treated cysts were centrifuged at $650 \mathrm{~g}$ for $5 \mathrm{~min}$. and suspended in distilled water to $10 \times 10^{6} \mathrm{cysts} / \mathrm{ml}$.; $0.1 \mathrm{ml}$. of this suspension was added to $0.9 \mathrm{ml}$. aqueous extract of $E$. coli and the excystment followed as reported earlier (Rastogi et al. 1969). 


\section{RESULTS}

Table I shows that ultrasonic treatment of double-walled cysts (Pl. I, fig. I) removed the outer wall and increased the number of single-walled cysts (P1. I, fig. 2). A decrease in the total count (normal and single-walled cysts) was also observed, indicating cyst disintegration. Affter $2 \mathrm{~min}$., $59 \%$ of the cysts were converted to single-walled structures, and $29 \%$ of the cysts were completely disrupted. After more than $3 \mathrm{~min}$. treatment, the residual population comprised almost entirely single-walled cysts. The single-walled cysts obtained by ultrasonic treatment excysted readily in Escherichia coli

Table I. Effect of ultrasonic treatment of cysts of Schizopyrenus russelli

$\begin{array}{cccc}\begin{array}{c}\text { Exposure time } \\ \text { (min.) }\end{array} & \text { Double-walled } & \text { Single-walled } & \begin{array}{c}\text { Disrupted } \\ \text { completely }\end{array} \\ 0 & \text { I00 } & 0 & 0 \\ \frac{1}{2} & 75 & 17 & 8 \\ \text { I } & 30 & 47 & 23 \\ 2 & \mathrm{I} & 59 & 29 \\ 3 & 2 & 53 & 45 \\ 5 & \mathrm{I} & 25 & 74 \\ 10 & 0 & 5 & 95\end{array}$

Table 2. Effect of p-chloromercuric benzoate on excystment of ultrasonically treated single-walled cysts of Schizopyrenus russelli

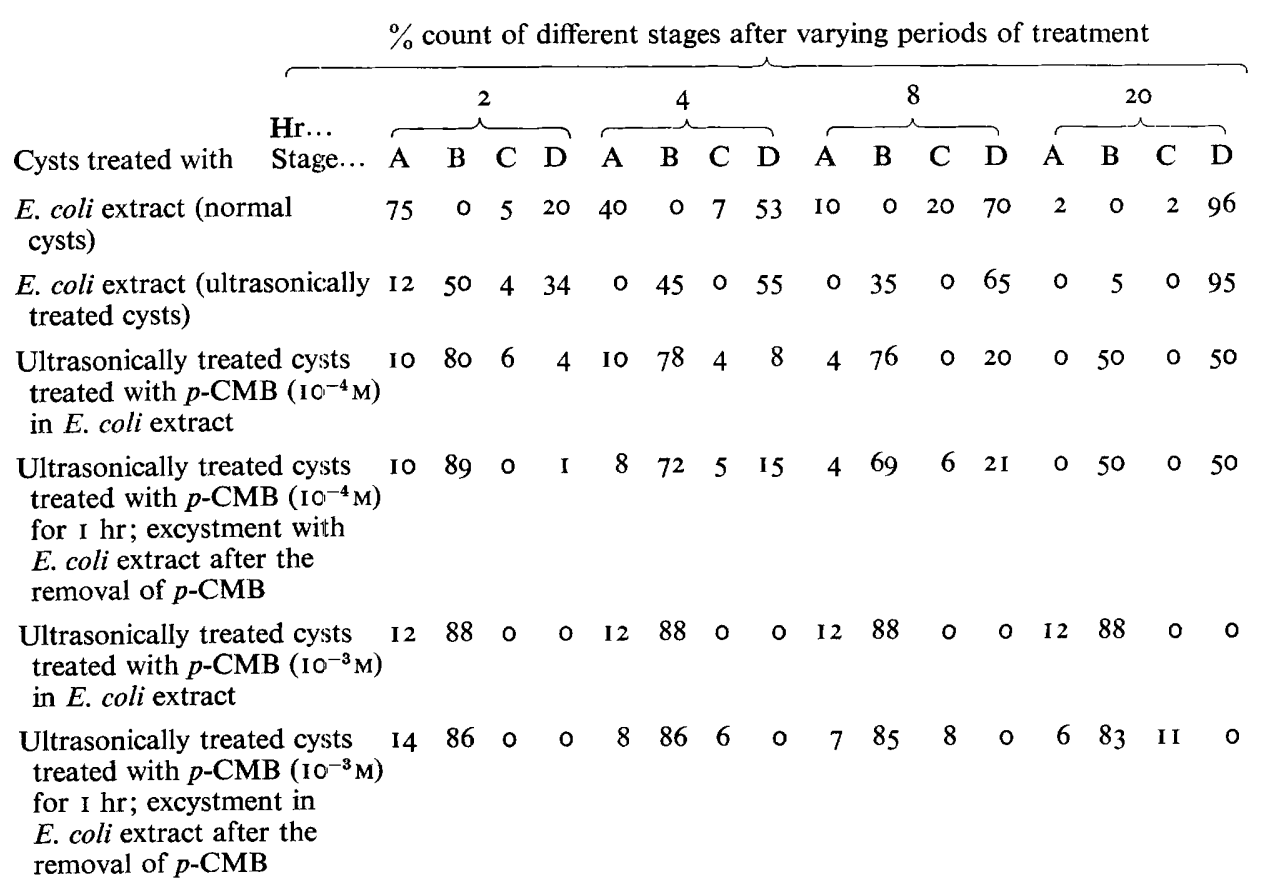

A, Double-walled cysts; B, single-walled cysts; C, cysts in the process of excystment; D, trophozoites. Ultrasonic treatment time $3 \mathrm{~min}$. 
extract, as did normal double-walled cysts (Tables, 2, 4 and 6). The majority of them did not take eosin staining $(0 \cdot 125 \%, \mathrm{w} / \mathrm{v})$, suggesting that the cysts were viable.

\section{Effect of $p-C M B$ on excystment of single-walled cysts}

The excystment of single-walled cysts of Schizopyrenus russelli was similar to that of the double-walled cysts (Table 2). When the single-walled cysts were treated with $p$-CMB $\left(\mathrm{IO}^{-4} \mathrm{M}\right)$ in Escherichia coli extract, there was a marked delay in excystment. Similar results were obtained when the cysts were treated with $p$-CMB $\left(\mathrm{IO}^{-4} \mathrm{M}\right)$ in water, washed in distilled water and then put for excystment in $E$. coli extract. Under both these conditions cysts treated with $10^{-3} \mathrm{M} p$-CMB failed to excyst in $20 \mathrm{hr}$. Reduced glutathione (GSH) annulled the $p$-CMB effect, both when added with $p$-CMB and after removal of the latter (Table 3). There was a marked delay in excystment of the single-walled cysts of $S$. russelli obtained by sonication of the normal cysts treated with $p$-CMB (Table 4 ). These findings suggest that $p$-CMB is able to permeate the outer cyst wall of double-walled cysts.

Table 3. Annulment of p-CMB delayed excystment of ultrasonically treated Schizopyrenus russelli cysts by reduced glutathione

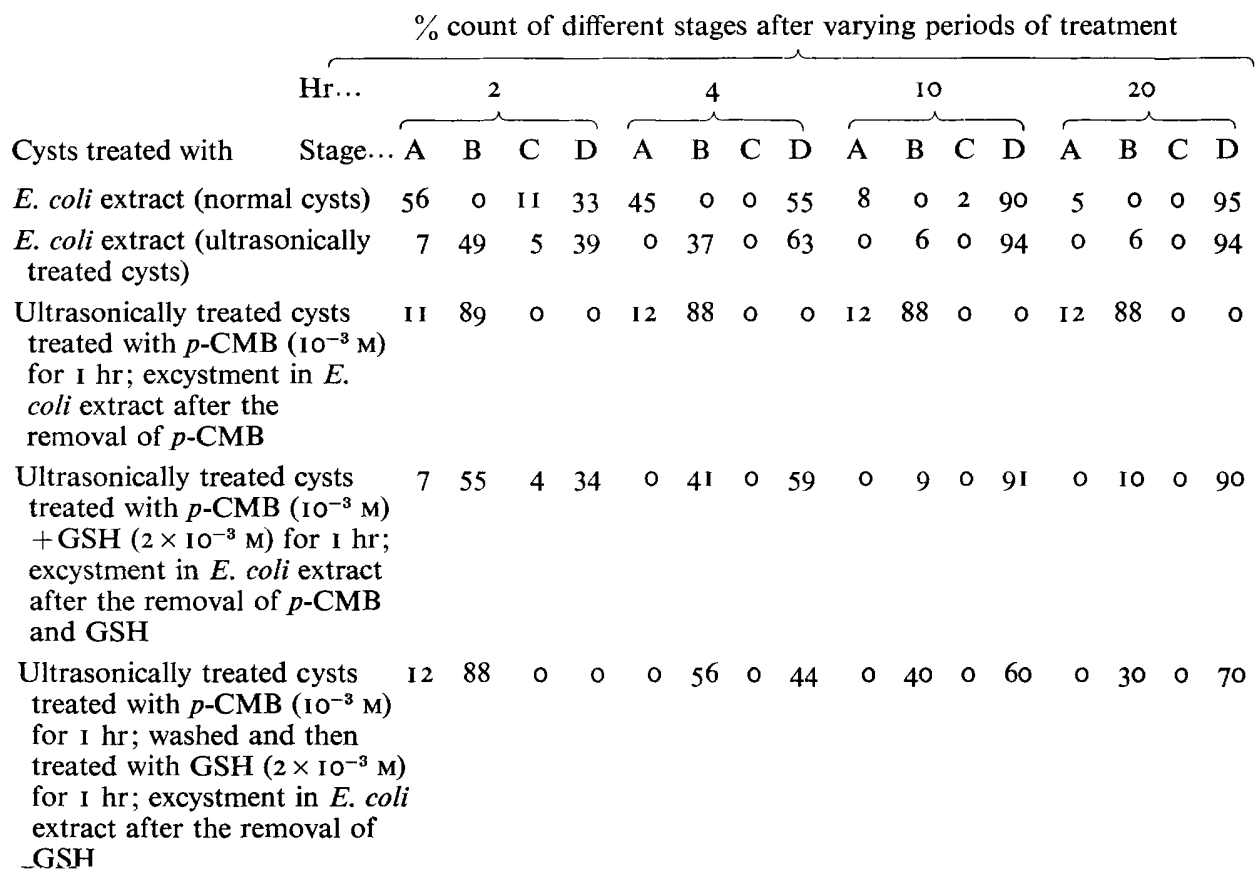

A, B, C and D as in Table I. Ultrasonic treatment for $3 \mathrm{~min}$.

\section{Effect of emetine on excystment of normal and ultrasonically treated cysts}

The results in Table 5 indicate that, even after the removal of emetine, there was a delay in excystment which was proportional to the concentration of emetine. Ultrasonically treated single-walled cysts were also sensitive to the action of emetine (Table 6) and the delay in excystment increased with its concentration. The maximum 
excystment obtained in $24 \mathrm{hr}$ after incubation and removal of emetine (Io $\mathrm{mg} . / \mathrm{ml}$.) was around $50 \%$ (Tables 4 and 5). The residual cysts, however, excysted almost completely in another $24 \mathrm{hr}$ when incubated with fresh bacterial extract.

When emetine-treated normal cysts were subsequently treated ultrasonically, a

Table 4. Delay in excystment of single-walled cysts of Schizopyrenus russelli (obtained by ultrasonic treatment of normal cysts treated with p-CMB or emetine)

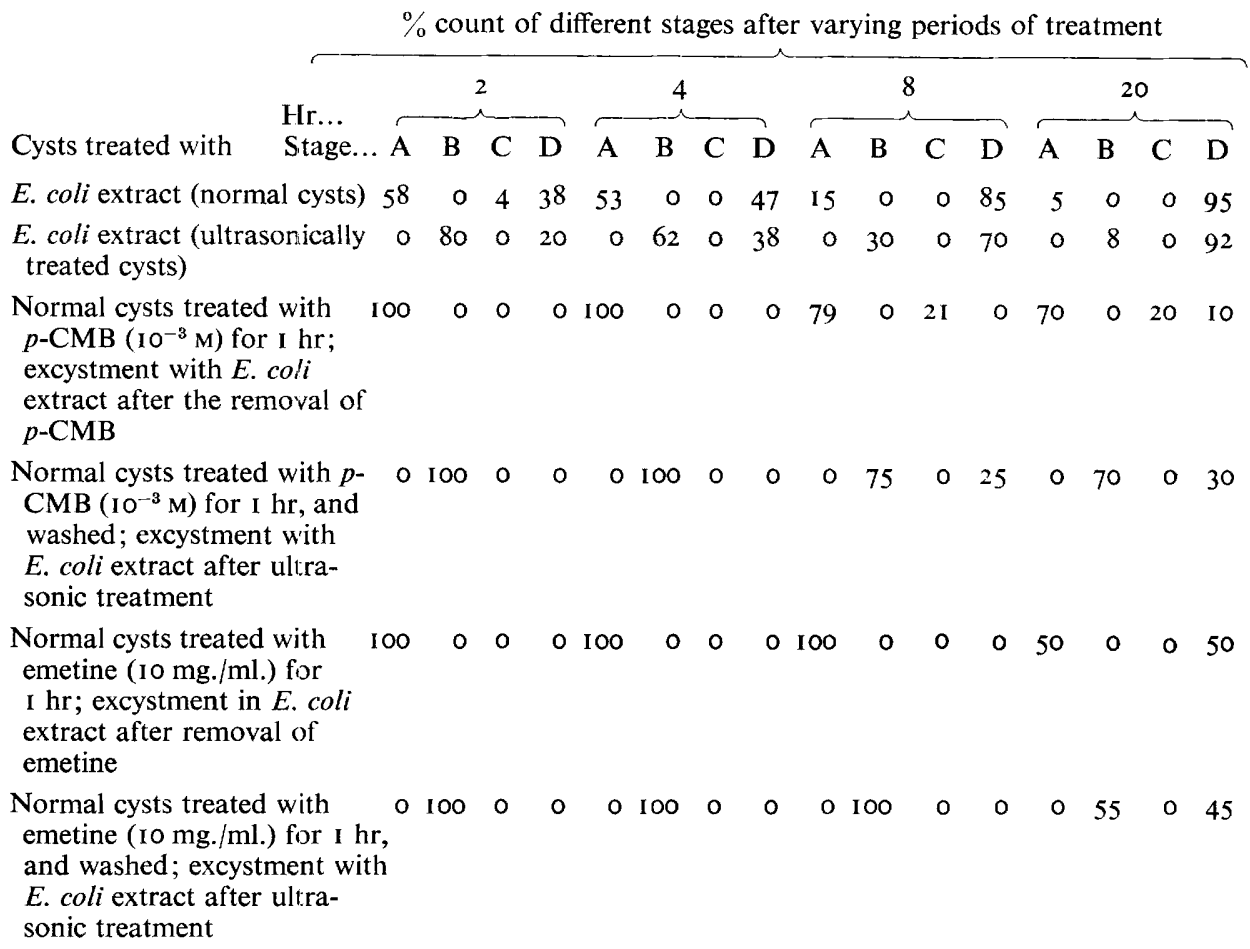

A, B, C, and D as in Table I.

Table 5. Delay in excystment of normal cysts of Schizopyrenus russelli treated with emetine

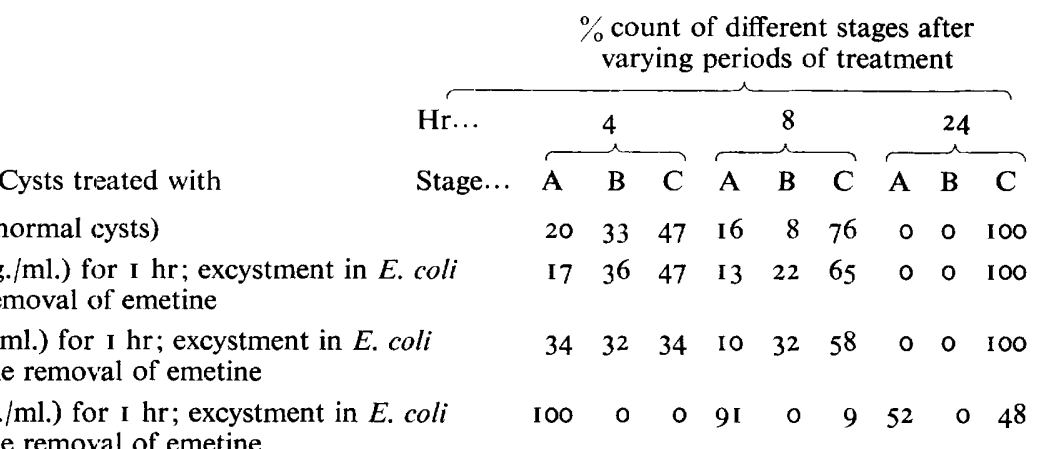
extract after the removal of emetine

A, Double-walled cysts; B, cysts in the process of excystment; C, trophozoites. 
delay in excystment was still observed in the resulting single-walled cysts, as found with $p$-CMB (Table 4), showing that emetine also was able to permeate the outer cyst wall of normal double-walled cysts.

Table 6. Delay in excystment of ultrasonically treated cysts of Schizopyrenus russelli treated with emetine

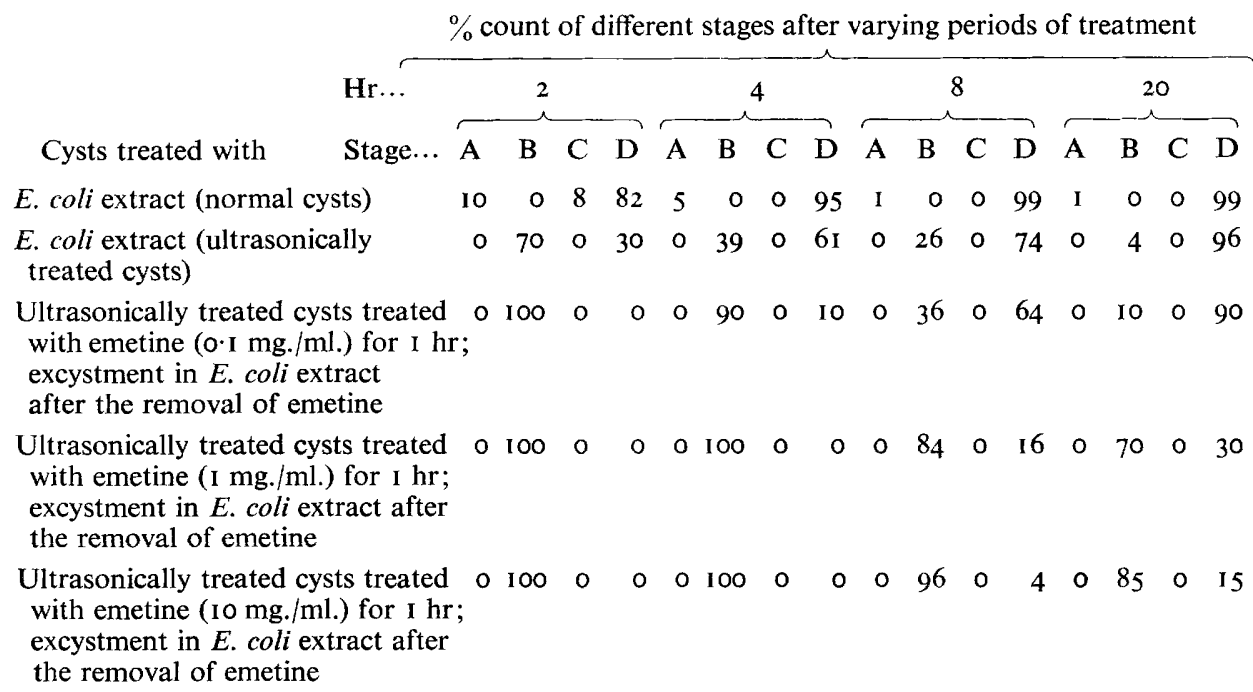

A, B, C and D as in Table $\mathrm{I}$. Ultrasonic treatment for $3 \mathrm{~min}$.

\section{DISCUSSION}

Ultrasonic treatment of Schizopyrenus russelli cysts gave single-walled structures. These single-walled cysts excysted in Escherichia coli extract as readily as the normal double-walled cysts. This suggests that the site of interaction with the excystment factors is located either on or within the inner cyst wall and that the excystment agents are able to permeate the outer cyst wall to trigger the excystment mechanism in normal cysts. The marked delay in excystment of single-walled cysts after treatment with $p$-CMB or emetine was similar to that obtained with normal cysts, and suggests that these agents are able to permeate the outer cyst wall. The delay in excystment depended on the concentration of $p$-CMB and emetine used.

The fact that $p$-CMB- and emetine-treated cysts were viable and could excyst after longer incubation in the bacterial extract shows that the damage caused by these agents is repairable by factors inherent within the cysts or in the excystment medium.

The authors' thanks are due to Dr B. N. Singh, Scientist-in-charge of the Microbiology Division, for helpful suggestions in the preparation of the manuscript. The authors are also thankful to Mr L. M. P. Singh and Mr R. B. Lal for technical assistance throughout these investigations. 


\section{REFERENCES}

ImaM, S. A., DutTA, G. P. \& Agarwala, S. C. (1968). Inhibition of excystment of Schizopyrenus russelli cysts in the presence of emetine and its cysticidal effect in conjunction with Sodium lauryl sulphate. Journal of General Microbiology 51, 17.

Rastogi, A. K., Sagar, P. \& AGarwala, S. C. (1969). Marked delay in excystment of Schizopyrenus russelli cysts by $p$-chloromercuric benzoate and its reversal with reduced glutathione. Journal of General Microbiology 56, 289.

Singh, B. N., Mathew, S. \& Anand, N. (1958). The role of Aerobacter sp., Escherichia coli and certain amino acids in the excystment of Schizopyrenus russelli. Journal of General Microbiology 19, 104.

\section{EXPLANATION OF PLATE}

Fig. I. Normal double-walled cysts of Schizopyrenus russelli.

Fig. 2. Ultrasonically treated single-walled cysts of $S$. russelli after the removal of the outer wall. 


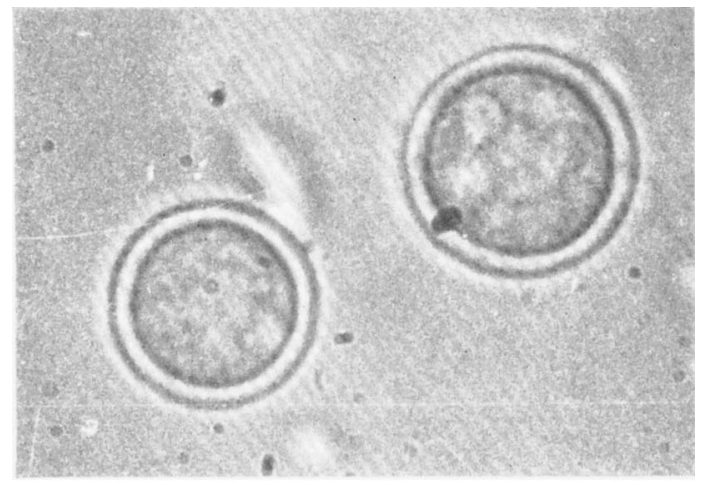

Fig. I

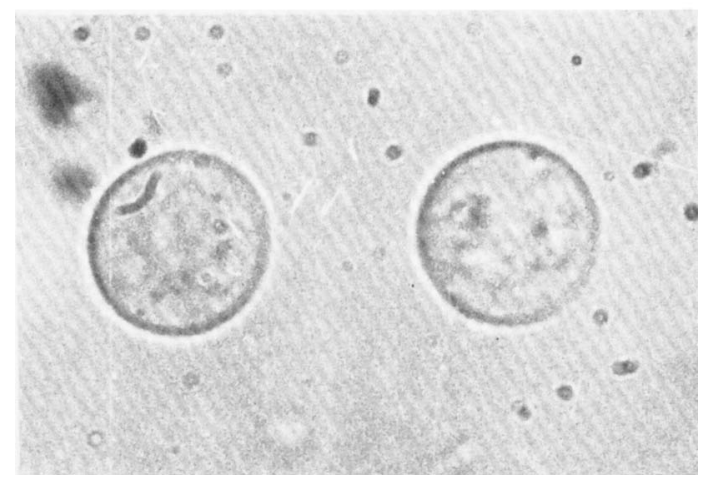

Fig. 2 